\title{
INOVAÇÃO CURRICULAR E INOVAÇÃO PEDAGÓGICA: MUDANÇAS PARADIGMÁTICAS NA FORMAÇÃO DO PROFESSOR UNIVERSITÁRIO'
}

\author{
CURRICULAR INNOVATION AND PEDAGOGICAL INNOVATION: \\ PARADIGMATIC CHANGES IN THE TRAINING OF UNIVERSITY PROFESSORS \\ INNOVACIÓN CURRICULAR E INNOVACIÓN PEDAGÓGICA: CAMBIOS \\ PARADIGMÁTICOS EN LA FORMACIÓN DEL PROFESOR UNIVERSITARIO
}

\author{
Amanda Rezende Costa Xavier* \\ Maria Antonia Ramos de Azevedo** \\ Ligia Bueno Zangali Carrasco***
}

\begin{abstract}
*Doutoranda em Educação pela Universidade Estadual Paulista "Julio de Mesquita Filho" (Unesp), na linha de pesquisa Linguagem - Experiência - Memória Formação, com período sanduíche na Faculdade de Psicologia e de Ciências da Educação, na Universidade do Porto, Portugal. Mestre em Educação pela Unesp e graduada em Pedagogia pelo Centro Universitário do Sul de Minas. É membro do Grupo de Estudos e Pesquisas em Pedagogia Universitária (Geppu), da Unesp Rio Claro, registrado no diretório do Conselho Nacional de Desenvolvimento Científico e Tecnológico (CNPq). Atualmente, é Pedagoga no Campus Avançado da Universidade Federal de Alfenas (UNIFAL). Poços de Caldas, Minas Gerais, Brasil. E-mail: arezendexavier@ hotmail.com
\end{abstract}

**Doutora em Educação pela Universidade de São Paulo (USP) e Pós-doutora em Pedagogia Universitária pela Universidade do Vale do Rio dos Sinos (Unisinos). Mestre em Educação pela Universidade Federal de Santa Maria (UFSM) e graduada em Pedagogia pela Pontifícia Universidade Católica de São Paulo (PUC-SP). Foi ViceDiretora do Instituto de Biociências da Unesp, no período de 2015 a 2019, Campus Rio Claro, onde é professora na área de Didática. É líder do Geppu e do Grupo de Pesquisa em Formação de Professores, Ensino e Avaliação da Unisinos, também registrado no CNPq. Piracicaba, São Paulo, Brasil. E-mail: maria.antonia@unesp.br

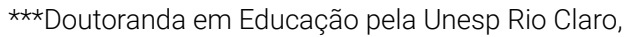
com estágio na Universidade de Buenos Aires (UBA). É membro do Geppu e Mestre em Educação pela Unesp na linha de pesquisa Linguagem - Experiência Memória - Formação. É graduada em Pedagogia pela mesma universidade. Rio Claro, São Paulo, Brasil. E-mail: li_carrasco@yahoo.com.br

Recebido para publicação em 8.1.2019

Aprovado em 16.9.2019

\section{Resumo}

Este estudo, ancorado em abordagem qualitativa, trata da formação pedagógica docente em contexto de inovação curricular. O locus foi uma universidade federal concebida sob o modelo da Universidade Nova, e os participantes, 34 docentes que estiveram em formação pedagógica entre 2014 e 2017. Os dados obtidos apontam que, apesar de os processos de construção de saberes da docência terem sido organizados sistematicamente, os docentes têm dificuldade em consolidar a ruptura paradigmática necessária à inovação pedagógica.

Palavras-chave: Pedagogia universitária. Desenvolvimento profissional docente. Formação pedagógica. Inovação curricular. Inovação pedagógica.

\section{Abstract}

This study, anchored on a qualitative approach, examines the pedagogical training of teachers in the context of curricular innovation. The locus was a federal university conceived under the New University model, and the participants were 34 teachers who underwent their pedagogical training between 2014 and 2017. Data show that, althoughtheprocesses of construction ofteaching knowledge have been systematically organized, teachers have difficulty in consolidating the paradigmatic rupture necessary for pedagogical innovation. 
Keywords: University pedagogy. Teaching professional development. Pedagogical training. Curriculum innovation. Pedagogical innovation.

\section{Resumen}

Este estudio, basado en un enfoque cualitativo, trata sobre la formación pedagógica docente en un contexto de innovación curricular. El locus fue una universidad federal concebida bajo el modelo de la Universidad Nueva, y los participantes, 34 docentes que recibieron formación pedagógica entre 2014 y 2017. Los datos obtenidos señalan que, a pesar de que los procesos de construcción de saberes de la docencia han sido organizados sistemáticamente, los docentes tienen dificultad en consolidar la ruptura paradigmática necesaria para la innovación pedagógica.

Palabras clave: Pedagogía universitaria. Desarrollo profesional docente. Formación pedagógica. Innovación curricular. Innovación pedagógica.

\section{Introdução}

No atual cenário da educação brasileira, propostas de reestruturações curriculares relacionadas a processos de ampliação e democratização do acesso ao ensino superior afetam as lógicas internas da universidade. Esses processos, no campo sociopolítico, permitem atingir uma reivindicação social crescente, que provém, principalmente, de uma grande parcela da população desde sempre apartada da formação universitária, por ser reflexo de um cenário político, social e educacional bastante desigual (SANTOS; ALMEIDA FILHO, 2008).

Assim, o público que hoje em dia acessa o ensino superior já não compõe a elite que historicamente frequentou a universidade. Não obstante, ingressam agora nessa etapa educacional estudantes de origens bastante heterogêneas, muitas vezes, dotados com menor capital social e cultural, o que modifica as expectativas sobre a formação universitária oferecida e, por conseguinte, modifica as salas de aulas e os espaços acadêmicos.

Logo, a democratização do ensino superior e os apelos sociais exigem da universidade novas abordagens e novos resultados nos processos de ensinar e aprender no ensino superior (CUNHA, 2010a; LEITE, 2010; SANTOS; ALMEIDA FILHO, 2008). No domínio pedagógico, inserem-se elementos que exigem a inovação das práticas, de modo a ser atingida toda a gama de perfis de estudantes. A evasão e o insucesso acadêmico deixam de ser vistos com naturalidade, e surge a demanda por procedimentos que garantam a qualidade do processo de ensino e aprendizagem.

Desse modo, os docentes universitários se veem perante um público heterogêneo, um modelo curricular cujos pilares não dominam e uma necessidade de reconfigurar suas práticas para atender às exigências que se constituem no exercício da docência. 
Tendo em vista essa realidade, os caminhos percorridos para engendrar o artigo agora apresentado se ancoraram em abordagem qualitativa de pesquisa. A delimitação do locus se deu em um campus universitário que vivencia diariamente o contexto de inovação curricular da Universidade Nova². A universidade federal escolhida, situada no sul do estado de Minas Gerais, era, originalmente, uma escola de nível superior, fundada em 1914, e somente em 2005 foi transformada em Universidade Federal.

\section{Inovação curricular} implica inovação pedagógica?
A referida universidade foi parte das ações do Programa de Apoio a Planos de Reestruturação e Expansão das Universidades Federais (Reuni), assim passando de uma instituição de ensino superior da área de Saúde, até então com sete cursos, para uma universidade com três campi, 33 cursos de graduação (dos quais três são na modalidade a distância) e 18 programas de pós-graduação (XAVIER; TOTI; AZEVEDO, 2017).

Assim, o histórico da instituição potencializa esta pesquisa porque, dentre os campi abertos, o campus escolhido para se desenvolver o estudo se respaldou totalmente na política do Reuni, passando a oferecer seu currículo sob a filosofia da Universidade Nova, com a oferta de um curso de Bacharelado Interdisciplinar em Ciência e Tecnologia. Nunca houve nesse campus o desenvolvimento de outra proposta curricular que não o modelo de inovação em questão.

Os participantes da pesquisa foram docentes da instituição, todos lotados no referido campus. No total, esse quadro de docentes contava, no fim das atividades diretas com os participantes, ou seja, no $2^{\circ}$ trimestre de 2017, com 84 docentes, dos quais, de acordo com os levantamentos do estudo, 93\% detinham a titulação de doutor. Como o modelo curricular desse campus se estrutura no curso de Bacharelado Interdisciplinar, os docentes representam várias áreas do conhecimento, dentre as quais estão Ciências Exatas, da Natureza, da Terra, Humanas e Sociais Aplicadas, além da Engenharia.

O percurso metodológico para esta pesquisa primou pela oferta de formação pedagógica aos docentes que atuam na proposta curricular. A investigação visava oportunizar a construção de um espaço de discussão e reflexão coletiva sobre a atuação profissional docente. Essas atividades se dividiram em quatro momentos de formação, transcorridos no período de 2014 a 2017.

Todo o quadro docente do referido campus foi convidado a participar, sendo efetiva a colaboração de 34 professores, todos com titulação de doutor. Visto que o campus em estudo conta com 84 docentes efetivos, a participação representou cerca de $40 \%$ do corpo docente. Esse número, abaixo da metade do efetivo de professores convidados, corrobora as conclusões verificadas na literatura no que diz respeito à dedicação desses profissionais às atividades específicas de área, notadamente à pesquisa em seu campo de conhecimento, em detrimento da formação pedagógica necessária à prática docente (CUNHA, 2010a; LEITE, 2010). 
Sendo assim, o objetivo deste estudo é refletir sobre a formação pedagógica do docente universitário, entendida como componente do desenvolvimento profissional. Ao buscar responder à questão: "Inovação curricular implica inovação pedagógica?", considerou-se a necessidade de a formação pedagógica ser acionada em contexto de inovação curricular, uma vez refletidas as concepções elaboradas pelos professores e os desafios por eles vivenciados para construir saberes da docência. As compreensões elaboradas, conferidas pelas falas dos participantes, faceiam as conjecturas assumidas neste estudo, permitindo refletir sobre os desafios que se instalam e dificultam a inovação pedagógica das práticas desenvolvidas pelos docentes em contextos curriculares inovadores.

\section{Inovação curricular: a proposta da Universidade Nova}

O discurso pedagógico em torno da reestruturação do ensino superior brasileiro se modela, em boa medida, no discurso que embasa a Declaração de Bolonha, documento conjunto dos Ministérios da Educação europeus, reunidos em Bolonha em 19 de junho de 1999. As questões que envolvem a autonomia dos estudantes no processo de aprendizagem e a competência de aprender ao longo da vida compõem a base do discurso em torno do Processo de Bolonha (LEITE, 2010) - e podem ser também percebidas no modelo de reestruturação do ensino superior brasileiro.

No caso do Brasil, as discussões sobre a necessidade dessa reestruturação se deram entre Ministério da Educação (MEC) e Associação Nacional dos Dirigentes das Instituições Federais de Ensino Superior (Andifes). Ambos assinalaram estratégias de reforma do ensino superior brasileiro, possíveis se currículos e projetos pedagógicos de curso fossem revisados, flexibilizados e tornados interdisciplinares, com base em uma alta formação crítica e humanística.

Nesse contexto de discussões compatibilizadas com a filosofia europeia, sancionada pela Declaração de Bolonha, surge o modelo da Universidade Nova como proposta de reestruturação curricular do ensino superior brasileiro. O modelo busca a flexibilização do currículo, partindo para uma arquitetura que contemple os grandes eixos de conhecimento (SANTOS; ALMEIDA FILHO, 2008) em um sistema de ciclos, que permita criar paradigmas no panorama educacional brasileiro.

A Universidade Nova representa um modelo filosófico-curricular ancorado em uma confıguração diferente do ensino superior brasileiro. Caracteriza-se por ciclos que permitem acesso a várias opções de saída para um segundo ciclo de formação e abrange a graduação bacharelado ou licenciatura, a pós-graduação ou o ingresso no mundo do trabalho. O primeiro ciclo, batizado de Bacharelado Interdisciplinar, representa uma alternativa avançada de estudos superiores, pois reúne um conjunto de características que vêm sendo requeridas pelo mundo do trabalho e pela sociedade contemporânea (SANTOS; ALMEIDA FILHO, 2008). 
O Reuni, por sua vez, instituído pelo Decreto n. 6.096, de abril de 2007, foi a política que fomentou a implantação desse modelo curricular no Brasil, nas universidades federais que desejaram aderir às propostas de reestruturação e expansão. Logo, essa não foi uma opção de todas as universidades federais do país, sendo que, de acordo com levantamentos realizados no estudo, no ano de 2016, havia 23 universidades federais que tinham implantado cursos de Bacharelado Interdisciplinar.

As diretrizes do Reuni visam promover percursos acadêmicos que levem à formação de indivíduos aptos a enfrentar os desafios do mundo contemporâneo. Além disso, incentivam ações que aumentem substancialmente o número de vagas oferecidas nossas universidades federais do país, democratizando o acesso ao ensino. As referidas diretrizes definem a remodelagem curricular dos cursos oferecidos nessas instituições de ensino, valorizando interdisciplinaridade, flexibilidade, diversificação das modalidades de graduação e articulação com a pós-graduação, por meio da revisão de currículos e projetos acadêmicos, com o objetivo de proporcionar aos estudantes formação multi e interdisciplinar, humanista e com espírito crítico. Apontam também aspectos prioritários, dentre os quais estão a existência de um currículo flexível nos cursos de graduação, o que permite a construção de

Inovação curricular pode ser motivadora e estimuladora da inovação pedagógica diversificados itinerários formativos, que valorizam a possibilidade de mobilidade estudantil e ofertam formação e apoio pedagógico aos docentes da educação superior (BRASIL, 2007).

Essa proposta de reestruturação do ensino superior brasileiro sustenta pilares inovadores, o que leva a entendê-la como inovação curricular. Lucarelli (1994) concebe que a inovação é necessária em contextos cuja situação habitual tende a distanciar-se de práticas inovadoras. Dessa forma, ela ocorre por meio de diferentes formas de organizar recursos humanos e materiais para o alcance de fins e objetivos definidos. Assim, é a ruptura com práticas tradicionais, protagonizadas conscientemente na realidade acadêmica.

Se, portanto, entende-se a inovação como processo de ruptura paradigmática (CUNHA, 2010a; LUCARELLI, 1994), visualiza-se a necessidade de inovação pedagógica das práticas docentes para que os objetivos formativos tenham coerência. Acerca disso, 70\% dos docentes participantes desta pesquisa afirmaram que a inovação curricular não é suficiente para que haja inovação pedagógica: revelaram que a inovação curricular pode ser motivadora e estimuladora da inovação pedagógica, mas não suficiente. Reafirmaram ainda que a mudança está no comportamento docente, que precisa deixar de ser estritamente disciplinar e setorizado para que se possa chamar de inovação pedagógica.

Entende-se, contudo, que a inovação pedagógica das práticas docentes não se reconfigura sozinha, o que reforça a importância da oferta institucional de formação pedagógica orientada para o desenvolvimento profissional dos docentes. A formação pedagógica se configura como recurso para a construção de saberes que sustentem essa inovação e permitam a alteração paradigmática, chamada pelos docentes de "comportamento". 


\section{Inovação pedagógica: o desafio do desenvolvimento profissional e da formação pedagógica na construção de saberes da docência}

A percepção dos participantes revela que a inovação pedagógica não acontece espontaneamente após a implantação de inovações curriculares no ensino superior, de modo que fica evidente a importância que a formação pedagógica tem perante os desafios que se apresentam aos profissionais da docência, que deverão atender às novas exigências para o ensino superior. Contudo, é necessário atentar para questões que orientam esse processo, dentre as quais se situa a institucionalização de espaços de formação pedagógica docente, bem como a concepção de inovação pedagógica como ruptura epistemológica.

Assim, a institucionalização dos espaços de formação se refere a um processo que diz respeito à imposição de normas ou definições unilaterais da instituição. Trata-se da promoção e valorização, em níveis institucionais, de espaços coletivos de construção de saberes; concerne à horizontalidade da construção de espaços formativos (XAVIER, 2014), que se transformam em lugares de formação (CUNHA, 2010a), concebidos como responsabilidade conjunta entre docentes e instituição (DAY, 1999) em um compromisso institucional (CUNHA, 2014).

Por sua vez, a concepção de desenvolvimento profissional, que deve sustentar os espaços institucionais de construção dos saberes da docência, trata de um processo de formação permanente, que tem lugar ao longo da vida profissional do docente, suportado por uma atitude de constante aprendizagem profissional facilitada pelo acesso a espaços de troca e de construção de novos saberes. É um sistema encadeado pela aquisição de experiência e tomada de consciência profissional, que insere o professor na cultura da docência e lhe dá competência para nela se situar e transformar seu espaço de atuação (DAY, 1999; GARCIA, 1999; VAILLANT, 2009).

Logo, vislumbra-se, para o desenvolvimento profissional docente, a necessidade de ruptura com as concepções de formação que se configuram como mero treino, cujo foco é apenas o desenvolvimento de técnicas de trabalho. Pelo contrário, assumindo-se a formação do docente como processo, no qual os docentes "se implicam individualmente ou em equipe, em experiências de aprendizagem" (GARCIA, 1999, p. 26), a formação aqui defendida vê o docente como sujeito da formação, isto é, aquele que protagoniza a construção de seus saberes, compartilhando experiências e reflexões, buscando o compromisso da transformação.

Acerca da formação pedagógica contida nos programas de desenvolvimento profissional docente institucionalizados, os participantes do estudo afirmaram que esperavam receber da instituição orientação sobre como desenvolver práticas interdisciplinares, com vistas à sua inserção no modelo curricular. A totalidade dos participantes afirmou, ainda, acreditar que a formação pedagógica oferecida pelos programas institucionais colabora para o enfrentamento dos desafios vivenciados na docência, principalmente nesse modelo curricular do Bacharelado Interdisciplinar. 
Essa crença corrobora a ideia de institucionalização dos espaços de formação pedagógica com vistas à promoção do desenvolvimento profissional. Contudo, apesar da crença nos processos de formação, a dedicação dos docentes para as questões pedagógicas e humanísticas do ensino não é valorizada

A formação do docente universitário deve ocorrer mediante ações proativas de reflexão e intervenção dos próprios atores na mesma intensidade que os conhecimentos e conteúdo específicos que ministram (CUNHA, 2010, 2010a, 2014). Tal realidade ficou evidente, inclusive, pelo fato de apenas $40 \%$ dos professores terem se disponibilizado a participar de alguma das atividades formativas oferecidas.

Nesse cenário, como promover a inovação das práticas a partir de uma formação pedagógica que provoque rupturas epistemológicas, se há predominância dos saberes da área de conteúdo, em sobreposição aos conhecimentos que sustentam uma prática fundamentada da docência?

\section{A busca por uma nova epistemologia na formação de profes- sores atuantes no modelo curricular da Universidade Nova}

As reflexões expostas, em face do projeto de formação pedagógica, que se orientou pela realidade vivenciada pelos docentes, ou seja, pelos problemas nascidos no meio deles, prolongou-se para além de uma atividade pontual de formação. Assim, ao longo do desenvolvimento do projeto, foram realizadas quatro atividades de formação pedagógica presenciais com temáticas próprias, mas interconectadas, de modo que se evidenciasse a progressão dos estudos. Essa estrutura formativa visava o entendimento de que a formação do docente universitário deve ocorrer mediante ações proativas de reflexão e intervenção dos próprios atores, em um processo de reflexão e ressignificação das práticas, ora nos momentos individuais, ora coletivos.

O primeiro encontro ocorreu em 17 de dezembro de 2014; o segundo em 18 de agosto de 2015; o terceiro em 6 de setembro de 2016; e o quarto e último encontro presencial transcorreu em 4 de abril de 2017. Para além dos encontros, foram previstos momentos individuais de estudos, estruturados em leituras relacionadas à complexidade da docência em contextos de inovação curricular. Também foram solicitadas escritas autorrefletidas sobre os saberes em construção e as práticas docentes no contexto de inovação discutido. Esses momentos individuais ocorreram de setembro de 2016 a abril de 2017, quando os professores realizaram as atividades de leitura e escrita propostas, de acordo com suas disponibilidades.

Na atividade de formação 1, intitulada "Universidade Nova: desafios para a prática pedagógica docente numa perspectiva interdisciplinar" (XAVIER, 2014), desenvolveram-se questões relacionadas ao contexto universitário, que exige práticas pedagógicas interdisciplinares, visando atender ao modelo curricular da Universidade 
Nova. A atividade contou com a participação de nove professores, sendo que desses, quatro atuaram como sujeitos de uma pesquisa de mestrado que recebeu o mesmo nome da atividade de formação. Ou seja, para 55\% dos participantes, a atividade foi a primeira oportunidade de refletir sobre a concepção docente acerca de conceitos como inovação curricular, inovação pedagógica e a necessidade da prática interdisciplinar como pilar do modelo pedagógico adotado pela Universidade Nova.

A atividade de formação 2, intitulada "Didática do Ensino Superior: conhecimentos e aprendizagens na prática pedagógica docente", buscou criar um espaço de reflexão em que os docentes pudessem analisar sua prática, de forma a compreenderem que o exercício da docência está muito além da transmissão de conhecimentos técnicos. Assim, o conceito trabalhado foi o de que a docência requer uma condução pedagógica do processo de ensino e aprendizagem no espaço da aula, e, nesse sentido, os conhecimentos e atitudes pedagógicas selecionados pelo docente se refletem na arte de ensinar. Dessa segunda atividade de formação participaram 19 professores, que foram convidados a formar três grupos que elencaram os conhecimentos, as habilidades e as atitudes que julgavam importantes no contexto de inovação pedagógica por eles vivenciados.

\section{Quadro 1 - Conhecimentos, habilidades e atitudes docentes}

\begin{tabular}{|c|c|c|c|}
\hline & Conhecimentos & Habilidades & Atitudes \\
\hline Grupo 1 & $\begin{array}{l}\text { Humanístico; Técnico/ } \\
\text { Aplicado; Científico; } \\
\text { Complementar } \\
\text { (interdisciplinar). }\end{array}$ & $\begin{array}{l}\text { Relacionar } \\
\text { conhecimentos; } \\
\text { Comunicação; } \\
\text { Empatia; Execução/ } \\
\text { Concretização; } \\
\text { Socialização; } \\
\text { Conciliação. }\end{array}$ & $\begin{array}{l}\text { Humildade; Proatividade; } \\
\text { Paciência; Perseverança; } \\
\text { Firmeza; Coerência; } \\
\text { Flexibilidade; Organização; } \\
\text { Dedicação; Urbanidade; } \\
\text { Criatividade; Bom senso. }\end{array}$ \\
\hline Grupo 2 & $\begin{array}{l}\text { Domínio do } \\
\text { assunto (conteúdo); } \\
\text { Conhecimento geral; } \\
\text { Conhecimento } \\
\text { pedagógico. }\end{array}$ & $\begin{array}{l}\text { Oratória; } \\
\text { Contextualização; } \\
\text { Comunicação; } \\
\text { Planejamento. }\end{array}$ & $\begin{array}{l}\text { Ética; Flexibilidade; } \\
\text { Coerência; Dedicação. }\end{array}$ \\
\hline Grupo 3 & $\begin{array}{l}\text { Técnico; Prática; } \\
\text { Métodos pedagógicos; } \\
\text { Oratória; Exemplos } \\
\text { cotidianos. }\end{array}$ & $\begin{array}{l}\text { Comunicação; } \\
\text { Uso de metáforas; } \\
\text { Percepção; } \\
\text { Criatividade; Saber } \\
\text { ouvir. }\end{array}$ & $\begin{array}{l}\text { Ética; Servir de exemplo; } \\
\text { Receptividade; Valorização } \\
\text { da participação discente. }\end{array}$ \\
\hline
\end{tabular}

Fonte: Quadro construído durante a Formação Pedagógica 3, pela mediadora Maria Antonia Ramos de Azevedo.

Conhecimentos, atitudes e habilidades foram apresentados pelos docentes de forma relacionada à prática pedagógica desenvolvida, pois a atividade permitiu observar que se reforçam os dados obtidos nas entrevistas, vez que todos os grupos, ao 
defenderem seus apontamentos, iniciaram os discursos pela validade do conhecimento técnico ou científico de suas áreas de especialização. Todos os participantes apontaram que o conteúdo é mais importante ante os demais saberes, reforçando o paradigma dominante de produção do conhecimento presente em um modelo curricular que exige atuação inovadora e, para tanto, rupturas. Outro dado que ratifica as observações acerca das entrevistas está no fato de identificarem pilares do modelo curricular inovador (como flexibilidade e interdisciplinaridade), porém, sem dar a ênfase devida ao modelo, o que faz considerar a fragilidade do ponto de vista conceitual pedagógico.

A atividade de formação 3, intitulada "Docência Universitária, Interdisciplinaridade e Inovação", teve como questão norteadora a discussão de como um currículo inovador pode ou não contribuir para inovações pedagógicas das ações profissionais dos professores. Ao construir saberes da docência, com vistas à orientação e fundamentação da inovação da prática pedagógica, a pesquisa buscou correlacionar o conceito de inovação curricular ao de inovação pedagógica, de modo a refletir sobre a dinâmica existente entre eles. Entretanto, para se alcançar essa relação, foi necessário percorrer discussões sobre a docência no ensino superior, a interdisciplinaridade e a flexibilidade como premissas para se atingir a inovação pedagógica requerida, o que levou à dinâmica de construção da teia interdisciplinar. A partir da ideia do todo foram-se especificando as áreas, passando pelas unidades curriculares que compõem o curso, para somente então se chegar aos conteúdos específicos de área. Dos 14 professores participantes, inicialmente, 57\% manifestaram interesse em tentar trabalhar essa lógica de construção dos conteúdos dentro de seus núcleos.

Figura 1 - Lógica da Teia Interdisciplinar

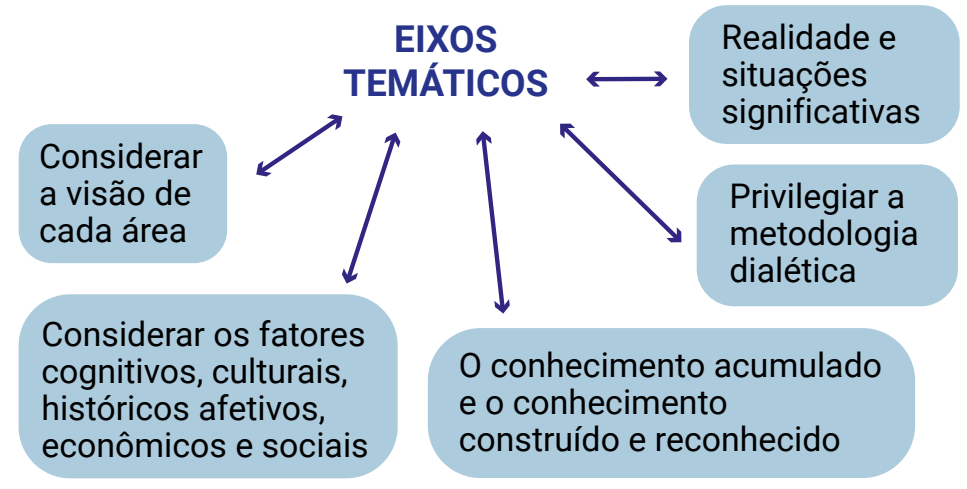

Fonte: Quadro construído durante a Formação Pedagógica 3, pela mediadora Maria Antonia Ramos de Azevedo.

Ao atingir-se a última atividade de formação, intitulada "Interfaces pedagógicas entre ação docente e programa de aprendizagem", o objetivo foi construir interfaces para a efetivação dos estudos na objetividade do planejamento da aula. A proposta 
de trabalho foi passar dos planos de ensino para os planos de aprendizagem, ou seja, o foco do processo sai do ensino do professor e se acomoda na aprendizagem do estudante (LEITE, 2010). Ao mesmo tempo, convida o docente a planejar as ações pedagógicas adotando o princípio epistemológico de construção de conhecimento mediante atitude metodológica interdisciplinar.

A essa altura, os docentes elencaram algumas considerações construídas coletivamente: compreenderam a necessidade da ruptura com o modelo tradicional de transmissão de conhecimento, a partir de uma nova visão quanto ao processo de ensino e de aprendizagem, lidando com a dúvida e com o questionamento como orientadores das ações docente e discente. Porém, apontaram seus

Como efetivar a prática requerida em planos de aprendizagem, e não em planos de estudos, agindo individualmente? maiores desafios em face dessa aprendizagem da docência: como dar o salto da prática individualizada para a prática coletiva, flexível e interdisciplinar? Como efetivar a prática requerida em planos de aprendizagem, e não em planos de estudos, agindo individualmente? Mesmo compreendendo os conceitos trabalhados, a ação, a prática, o "pôr à prova" ainda não estava claro para o grupo. Como desenvolver um trabalho cooperativo, com verificação contínua dos valores do grupo? Mesmo entendendo que o agir em cooperação levaria a produzir, retomar, corrigir, redirecionar os objetivos, ainda não tinham evidentes os caminhos para fazer acontecer a mudança, porque afirmaram que a maior parte dos docentes não quer despender esforços nesse tipo de reflexão.

Esses foram questionamentos e inquietações compartilhados pelos seis docentes participantes da atividade. O baixo número de participantes na última atividade de formação referendou as inquietações apresentadas, porque mesmo diante da preocupação em desenvolver um trabalho que demonstrasse continuidade no espaço-tempo da formação, rompendo com a prática formativa pontual, e buscando trabalhar temáticas que representam desafios para a prática daquele grupo de professores (ou seja, os desafios fazem parte de seu meio), ainda assim o corpo docente não participou. Essa não adesão incomodou aqueles que participaram, exponenciando neles as inquietações apresentadas, visto que os próprios estudos já os havia retirado do lugar isolado que a docência universitária, em nome de uma suposta autonomia, ocupou (CUNHA, 2010a).

Nesse sentido, apesar da formação proposta representar uma concepção de continuidade, em que se levou em consideração a cultura própria de cada área de atuação, de cada localidade, e que não apenas se propôs a transmitir conceitos, mas a ouvir necessidades postas e elementos emergentes (CARRASCO, 2016), esse modelo formativo também não atrai os docentes universitários de forma geral.

\section{Considerações finais}

Os espaços de formação de professores, pautados na busca por mudanças paradigmáticas envolvendo a interface entre inovação curricular e pedagógica, ain- 
da são um campo de atuação difícil. Diante disso, demonstra-se a necessidade de mais estudos e pesquisas que potencializem ações outras, as quais visem a qualidade da formação em todos os âmbitos institucionais.

Assim, este projeto, que se desenhou como aproximação a um modelo que contempla uma epistemologia de formação pedagógica que verdadeiramente desencadeie rupturas paradigmáticas na ação docente, na ausência de uma cultura instituída, não conseguiu atingir todos os professores do quadro convidado.

Nesse aspecto, é possível levantar uma contradição. Se há o entendimento de que formações pontuais não são capazes de romper com o que existe e transformar paradigmas, as formações que possuem o aspecto da continuidade, da reflexão acerca da própria ação docente visando sua ressignificação, não são atraentes aos docentes que se ocupam de outras questões no decorrer de seu cotidiano, especialmente da pesquisa. Assim, o dilema da ação formativa não está somente na concepção de formação pedagógica, que deve ser bem fundamentada e pautada na perspectiva de desenvolvimento profissional, balizando-as em uma ação investigativa dos próprios professores universitários acerca de suas práticas, mas está também nas concepções elaboradas pelos docentes sobre o universo da docência.

A mudança paradigmática nos processos de ensinar e aprender, portanto, representa um desafio a ser transposto, pois muitos docentes ainda não têm constituído a ação profissional da docência, e quando sim, a concepção que pauta suas ações está configurada no ato de transmissão de informações, e não na construção e nas relações entre as diferentes áreas dos conhecimentos.

Nesse cenário, ter uma proposta curricular inovadora, amparada legalmente em documentos político-educacionais, não é condição suficiente para que os propósitos de melhoria da educação sejam atingidos. A pergunta inicial, "Inovação curricular implica inovação pedagógica?”, fica, a essa altura, negativa, o que significa que para se concretizar a inovação curricular é necessário dotar as práticas pedagógicas docentes dos mesmos conceitos. Em outros termos, não basta existir a inovação curricular; é necessário conduzir a prática a uma inovação pedagógica, de tal forma que todos os objetivos e propósitos estejam alinhados, entendendo que essa mudança paradigmática deve estar no cerne da instituição, e não apenas na ação individualizada do docente.

Dessa maneira, acredita-se que um caminho para auxiliar a superação de tais desafios é a formação pedagógica docente permanente, de modo a caracterizar a concepção que o corpo docente tem a respeito de suas próprias práticas pedagógicas, possibilitando um efetivo desenvolvimento institucional. Ademais, é preciso analisar práticas inovadoras de práticas tradicionais, confrontando assim a realidade vivenciada com a concepção pedagógica requerida pelos modelos inovadores, bem como verificar se há atendimento a tais concepções ou se a inovação se mantém somente no papel. 


\section{Notas}

${ }^{1}$ A presente pesquisa teve financiamento do Ministério da Ciência, Tecnologia, Inovações e Comunicações (MCTI) e do Conselho Nacional de Desenvolvimento Científico e Tecnológico (CNPq).

${ }^{2} \mathrm{O}$ modelo pedagógico da Universidade Nova é contextualizado na seção 2 deste artigo.

\section{Referências}

BRASIL. Ministério da Educação. REUNI: reestruturação e expansão das universidades federais: diretrizes gerais. Brasília, DF: Ministério da Educação, 2007.

CARRASCO, Ligia Bueno Zangali. Assessorias pedagógicas das universidades estaduais paulistas: concepções dos espaços institucionais de formação do docente universitário. 2016. Dissertação (Mestrado em Educação) - Instituto de Biociências, Universidade Estadual Paulista, Rio Claro, 2016.

CUNHA, Maria Isabel da. (org.). Estratégias institucionais para o desenvolvimento profissional docente e as assessorias pedagógicas universitárias: memórias, experiências, desafios e possibilidades. Araraquara: Junqueira \& Marin Editores, 2014.

CUNHA, Maria Isabel da. (org.). Trajetórias e lugares da formação da docência universitária: da perspectiva individual ao espaço institucional. Araraquara: Junqueira \& Marin Editores, 2010.

CUNHA, Maria Isabel da. Impasses contemporâneos para a pedagogia universitária no Brasil: implicações para os currículos e a prática pedagógica. In: LEITE, Carlinda. (org.). Sentidos da pedagogia no ensino superior. Porto: CIIE/ Livpsic, 2010a. p. 63-74.

DAY, Christopher. Desenvolvimento profissional de professores: os desafios da aprendizagem permanente. Porto: Porto Editora, 1999.

GARCIA, Carlos Marcelo. Formação de professores: para uma mudança educativa. Porto: Porto Editora, 1999.

LEITE, Carlinda. (org.). Sentidos da pedagogia no ensino superior. Porto: CIIE/ Livpsic, 2010. 
LUCARELLI, Elisa A. Teoría y práctica como innovación en docência, investigación y actualización pedagógica. Buenos Aires: Universidad de Buenos Aires, Facultad de Filosofía y Letras, 1994.

SANTOS, Boaventura de Sousa. ALMEIDA FILHO, Naomar. A universidade no século XXI: para uma universidade nova. Coimbra: Edições Almeida, 2008.

VAILLANT, Denise. Políticas para un desarrollo profesional docente efectivo. In: MEDRANO, Consuelo Vélaz; VAILLANT, Denise (coord.). Aprendizaje y desarrollo profesional docente. Madrid: OEl, 2009, p. 29-38.

XAVIER, Amanda Rezende Costa. Universidade nova: desafios da prática pedagógica numa perspectiva interdisciplinar. 2014. Dissertação (Mestrado em Educação) - Instituto de Biociências, Universidade Estadual Paulista, Rio Claro, 2014.

XAVIER, Amanda Rezende Costa; TOTI, Michelle Cristine da Silva; AZEVEDO, Maria Antonia Ramos de. Institucionalização da formação docente: análise de um programa de desenvolvimento profissional. Revista Brasileira de Estudos Pedagógicos, Brasília, DF, v. 98, n. 249, p. 332-346, maio/ago. 2017. 